\title{
KNOWLEDGE ABOUT TUBERCULOSIS AMONG PATIENTS ATTENDING FAMILY PRACTICE CLINICS IN KARACHI
}

\author{
Ali Khan Khuwaja and Naushaba Mobeen
}

\begin{abstract}
OBJECTIVE: Tuberculosis is on the rise throughout the world and better understanding and knowledge about tuberculosis remains an important tool in its control. The objective of this study was to determine the level of knowledge about tuberculosis among patients attending Family Practice clinics in Karachi.

SETTING: Family practice clinics affiliated to a tertiary care hospital in Karachi, Pakistan during July to September 2003.

METHODS: Total 204 subjects aged 18 years and above were interviewed on convenient basis in a cross-sectional survey. Data was collected through a pre-tested structured questionnaire which comprised of socio-demographic variables and questions about cause, transmission, common clinical features and cure of tuberculosis.

RESULTS: Respondents were predominantly female (58\%) with an extended family structure $(\mathbf{7 8 \%})$. More than one-third $(35 \%)$ of the respondents were illiterate and almost a similar proportion (31\%) had received primary education. Only $39 \%$ of study subjects knew that tuberculosis is an infectious disease, $19 \%$ reported that there is an asymptomatic stage of infection, $33 \%$ said that it is curable with proper treatment while $51 \%$ considered tuberculosis as a preventable disease. Forty-five percent of respondents did not know about possible consequences of uncured cases and $61 \%$ did not know tuberculosis as one of the major health problems of Pakistan.

CONCLUSION: In this study, majority of study subjects had poor knowledge about tuberculosis, its prevention and magnitude. Proper knowledge and education about tuberculosis is vital to cope the challenge of this devastating disease. Family Practitioner, being first care providers to the community can play a critical role to raise knowledge about tuberculosis prevention.
\end{abstract}

KEY WORDS: Tuberculosis. Knowledge. Prevention. Family practice.

\section{INTRODUCTION}

Tuberculosis is a leading infectious cause of death worldwide. It is responsible for 2 million deaths including $26 \%$ of preventable adult deaths annually ${ }^{1,2}$. One-third of the world population is currently infected with tubercle bacillus, and nearly one percent of the world population is newly infected with tuberculosis each year. It means that every second someone in the world is newly infected with tubercle bacillus. ${ }^{1}$ According to World Health Organization (WHO), between the years 2000 and 2020, nearly one billion people will be newly infected, 200 million people will get sick and 35 million will die from tuberculosis, if control is not further strengthened. ${ }^{1}$ The burden of tuberculosis mainly lies in the developing countries. Ninety-five percent of tuberculosis cases and almost $98 \%$ of deaths from tuberculosis occur in developing countries. ${ }^{3}$ Pakistan is among the 22 countries with greatest burden of tuberculosis. In 1997, tuberculosis estimates for Pakistan were 261,000 new cases, putting the estimated incidence of 181 cases per
100,000 population $^{4}$ and in some areas of the country, prevalence figures observed were as high as $554 / 100,000$ cases $^{5}$.

A number of factors are responsible for this devastating health problem which includes noncompliance with control programs, inadequate diagnosis and treatment, increasing migration due to natural and men made disasters and emerging epidemic of HIVIAIDS. ${ }^{6}$ All these are fueled by population explosion, rising number of multiresistance tuberculosis, drug abusers and refugees, poor socio-economic conditions and lack of knowledge and awareness about tuberculosis. Pakistan, where a large number of the population is living below poverty line ${ }^{7}$ and have poor demographic, educational, economic and health indicators $^{8}$ with huge burden of refugees and migrants; prevention is the best safe-guard against the tuberculosis emergence. Prevention and control of tuberculosis need a number of factors to intervene. Provision of specific health information has proved successful in health education campaigns. ${ }^{9}$ Good knowledge about tuberculosis among general 
population is of prime importance in this regard. Thus, objective of this study was to assess the level of knowledge about tuberculosis among patients attending family practice clinics at a teaching hospital in Karachi, Pakistan. This work will help to evaluate the level of knowledge and understanding about tuberculosis and thus guide to design health promotion and public awareness programs in this regard.

\section{SUBJECTS AND METHODS}

This was a cross-sectional study conducted in family practice clinics affiliated with a tertiary care teaching hospital of private sector in Karachi, Pakistan. A pretested structured questionnaire was administered to collect the information. The questionnaire comprised of two sections; one for assessment of personal characteristics and other for assessing level of knowledge about tuberculosis. Personal characteristics included sex, age in years, marital status, first language, educational level, occupational (working) status, family structure (extended/nuclear) and monthly house-hold income. Knowledge assessment sections included questions about cause, sign/symptoms, consequences, cure, prevention and burden of tuberculosis. With an anticipated prevalence of knowledge of $50 \%$, bound of error of $07 \%$ and level of significance $05 \%$, at least 196 patients were required for interview. However, we approached a total of 240 adult patients aged 18 years and above, who attended the facility for any reason during the period of July to September 2003. Two hundred and four subjects agreed for interview, gave the consent to participate in the study and were interviewed by trained interviewers. On a convenience basis, about 8 - 10 subjects were interviewed daily. Those who reported present or past history of personal and or family for tuberculosis were excluded. Data was entered and validated by using Epi Info 6, and analyzed by using Statistical Package for Social Sciences (SPSS version 11.5). Descriptive analyses (frequencies and percentages) were calculated for different variables of interest.

\section{RESULTS}

The personal characteristics of the study population are presented in Table I. Overall, there was female preponderance $(58 \%)$, age group 26 - 40 years (49\%), married (71\%), having either no education or only primary education (66\%), living in extended family system (78\%) and those having total monthly income of $£ 10000$ Pakistani rupees (55\%). Urdu was the first language spoken by $(48 \%)$ respondents followed by Sindhi (22\%), Punjabi (17\%); while remaining $(13 \%)$ were categorized as others (Gujrati, Pushto and Balochi). Knowledge about tuberculosis cause/transmission and signs/symptoms is presented in Table II. Thirty-nine percent of the respondents correctly answered that tuberculosis is an infectious disease and only $19 \%$ reported that there is an asymptomatic stage of infection. Overall, $82 \%$ of the respondents knew at least one sign/symptom of tuberculosis and cough was the most frequently reported symptom by $66 \%$ of respondents. Forty-five percent of respondents did not know about any possible consequence of untreated disease. Knowledge about tuberculosis cure, prevention and burden is mentioned in Table III. Only 33\% of the respondents were aware that tuberculosis is a curable disease with proper treatment and 31\% reported that after cure of disease suffering person can live as a normal life. Fifty-one percent of the subjects knew that it is a preventable disease. In response to question that whether tuberculosis is a major health burden for Pakistan, only $39 \%$ of the respondents answered in affirmation.

\begin{tabular}{|c|c|}
\hline Characteristic $\mathrm{n}=204$ & Number (\%) \\
\hline $\begin{array}{l}\text { Sex } \\
\text { Male } \\
\text { Female } \\
\end{array}$ & $\begin{array}{l}86(42) \\
118(58) \\
\end{array}$ \\
\hline $\begin{array}{l}\text { Age in years } \\
18-25 \\
26-40 \\
>40\end{array}$ & $\begin{array}{l}43(21) \\
99(49) \\
62(30)\end{array}$ \\
\hline $\begin{array}{l}\text { Marital status } \\
\text { Married } \\
\text { Unmarried } \\
\end{array}$ & $\begin{array}{l}145(71) \\
59(29)\end{array}$ \\
\hline $\begin{array}{l}\text { Educational status } \\
\text { No education } \\
\text { Primary } \\
\text { Secondary/higher secondary } \\
\text { Graduate/post graduate }\end{array}$ & $\begin{array}{l}71(35) \\
63(31) \\
37(18) \\
33(16) \\
\end{array}$ \\
\hline $\begin{array}{l}\text { Family structure } \\
\text { Extended } \\
\text { Nuclear }\end{array}$ & $\begin{array}{l}159(78) \\
45(22)\end{array}$ \\
\hline $\begin{array}{l}\text { Occupation } \\
\text { Manual worker } \\
\text { Office job/professional } \\
\text { House wife/domestic worker }\end{array}$ & $\begin{array}{l}63(31) \\
45(22) \\
96(47) \\
\end{array}$ \\
\hline $\begin{array}{l}\text { Total monthly income in } \\
\text { Pakistani Rupees } \\
<5000 \\
5000 \text { to } 10000 \\
>10000 \\
\text { Did not mention }\end{array}$ & $\begin{array}{l}49(24) \\
63(31) \\
35(17) \\
57(28)\end{array}$ \\
\hline $\begin{array}{l}\text { First language } \\
\text { Urdu } \\
\text { Sindhi } \\
\text { Punjabi } \\
\text { Others }\end{array}$ & $\begin{array}{l}98(48) \\
45(22) \\
35(17) \\
26(13)\end{array}$ \\
\hline
\end{tabular}


TABLE I:

SOCIO-DEMOGRAPHIC CHARACTERISTICS OF STUDY POPULATION

TABLE II:

\begin{tabular}{|l|c|}
\hline Knowledge Variable & Number (\%) \\
\hline Cause of Tuberculosis & $79(39)$ \\
Germs (infection) & $53(26)$ \\
Inherited & $45(22)$ \\
Cigarette/alcohol & $27(13)$ \\
Don't know & $84(41)$ \\
\hline Asymptomatic stage of infection & $96(47)$ \\
Yes & $24(12)$ \\
No & \\
Don't know & \\
\hline Signs and symptoms of & $135(66)$ \\
Tuberculosis* & $51(25)$ \\
Cough/haemoptysis & $18(09)$ \\
Fever/night sweats & $35(17)$ \\
Chest pain & $16(08)$ \\
Weight loss/tiredness & $53(26)$ \\
Others & $86(42)$ \\
\hline Consequences of uncured & $92(45)$ \\
cases* & \\
Spread to other parts of the body & \\
Spread to other persons & \\
Don't know &
\end{tabular}

KNOWLEDGE ABOUT THE CAUSE, SIGNS AND SYMPTOMS OF TUBERCULOSIS AMONG STUDY POPULATION

*Multiple response questions, sum not equal to $100 \%$.

\begin{tabular}{|l|c|}
\hline Response to questions & Number (\%) \\
\hline $\begin{array}{l}\text { Is the Tuberculosis curable with } \\
\text { proper treatment? }\end{array}$ & \\
Yes & $67(33)$ \\
No & $94(46)$ \\
Don't know & $43(21)$ \\
\hline Do you think that after cure to & \\
disease patient can live a nor- & \\
mal life? & \\
Yes & $63(31)$ \\
No & $94(46)$ \\
Don't know & $47(23)$ \\
\hline Is Tuberculosis a preventable & \\
disease? & \\
Yes & $104(51)$ \\
No & $55(27)$ \\
Don't know & $45(22)$ \\
\hline Is Tuberculosis a major health & \\
problem of Pakistan? & $80(39)$ \\
Yes & $94(46)$ \\
No & $30(15)$ \\
Don't know & \\
\hline
\end{tabular}

\section{TABLE III:}

\section{KNOWLEDGE ABOUT THE CURE AND BURDEN OF TUBERCULOSIS AMONG STUDY POPULATION}

\section{DISCUSSION}

This study has identified a big gap of knowledge about tuberculosis in patients attending family practice clinics in Karachi. Majority of study subjects did not know about the cause of disease, mode of transmission and consequences of uncured cases. These findings are consistent with an epidemiological study conducted to assess the knowledge and attitude about tuberculosis among the general population in Philippines, where only a quarter of the respondents knew about the cause of disease and $21 \%$ of them knew about its mode of transmission. ${ }^{10}$ However, there was better understanding about the sign and symptoms of tuberculosis in our study subjects, where majority of the respondents knew that cough is more frequent symptom and majority also knew about at least one sign/symptom. These findings are consistent with a study conducted in Tanzania, ${ }^{11}$ where more than $87 \%$ of the respondents knew at least one sign/symptom and cough was the most frequently mentioned symptom/sign of tuberculosis. Though, Pakistan is among the countries with higher incidence and prevalence of tuberculosis but only $31 \%$ of our respondents knew the tuberculosis as one of the major health problems in the country. It is a significant finding as this lack of knowledge may lead to poor responsiveness to the prevention programs. The results of this study should be interpreted with caution as the study was facility based and not ideally representing the general population.

The community's knowledge and perceptions about tuberculosis are important in influencing healthseeking behaviors considering the peculiar issues related to its long-term medications and compliance. Appropriate knowledge is of prime importance for control and prevention of many diseases and tuberculosis is no exception. This study concludes that knowledge about tuberculosis among the persons attending family practice clinics in Karachi is low and highlights the importance for designing and implementing appropriate programs and interventions to disseminate the knowledge and information about tuberculosis in the general population. We also recommend more studies and research to assess knowledge and understanding about tuberculosis at larger and community basis. This should only be possible with integrated efforts by government and non-governmental health organizations, media and donor agencies alongwith active community participation. Family practitioner, being a backbone of 
any health care delivery system and as first contact health person for majority of the patients and their families can play a critical role in availing every opportunity of advocacy and counseling for health promotion and disease prevention specially about tuberculosis.

\section{REFERENCES}

1. World Health Organization. Tuberculosis. Fact Sheet number 104. Revised April 2000. Available at http://www.who.int/inf-fs/en/fact104.h Accessed July 2002.

2. Kochi A. The global tuberculosis situation and the new control strategy of the World Health Organization. Bull WHO 2001; 79 (1):71-75.

3. Last JM. Maxcy-Rosenau. Public Health and Preventive Medicine. $14^{\text {th }}$ edition. Appleton and Lange, 1998; Pp. 208-217.

4. World Health Organization. Global Tuberculosis
Control, WHO Report 1999. Geneva, Switzerland. 1999; WHO/CDS/CPC/TB/99.259.

5. Alvi AR, Hussain SF, Shah MA et al. Prevalence of pulmonary tuberculosis on the roof of the world. Int J Tubrc Lung Dis 1998; 2(11): 909-13.

6. Pilheu JA. Tuberculosis 2000: problems and solutions. Int J Tuberc Lung Dis 1998; 2(9): 696703.

7. Population Policy of Pakistan. Ministry of Population Welfare, Government of Pakistan, Islamabad, 2002. Pp. 1-3.

8. UNICEF. The state of the world's children 2003. New York, USA, 2003.

9. White GL Jr, Henthorne BH, Barnes SE et al. Tuberculosis: a health education imperative returns. J Community Health 1995; 20:29-57.

10. Navio JLP, Yuste MR, Pasicatan MA. Socioeconomic determinants of knowledge and attitude about tuberculosis among the general population

AUTHOR AFFILIATION:
Dr. Ali Khan Khuwaja (Corresponding Author)
Senior Instructor
Departments of Community Health Sciences and Family Medicine
The Aga Khan University
Stadium Road, Karachi - Pakistan
Dr. Naushaba Mobeen
Senior Instructor
Department of Community Health Sciences
The Aga Khan University
Stadium Road, Karachi - Pakistan

